This item was submitted to Loughborough's Research Repository by the author.

Items in Figshare are protected by copyright, with all rights reserved, unless otherwise indicated.

\title{
A test method and deterioration model for joints and cracks in concrete slabs
}

PLEASE CITE THE PUBLISHED VERSION

PUBLISHER

(C) Elsevier

LICENCE

CC BY-NC-ND 4.0

\section{REPOSITORY RECORD}

Arnold, Stuart J., Paul R. Fleming, Simon A. Austin, and Peter J. Robins. 2019. "A Test Method and

Deterioration Model for Joints and Cracks in Concrete Slabs". figshare. https://hdl.handle.net/2134/3901. 
This item was submitted to Loughborough's Institutional Repository (https://dspace.lboro.ac.uk/) by the author and is made available under the following Creative Commons Licence conditions.

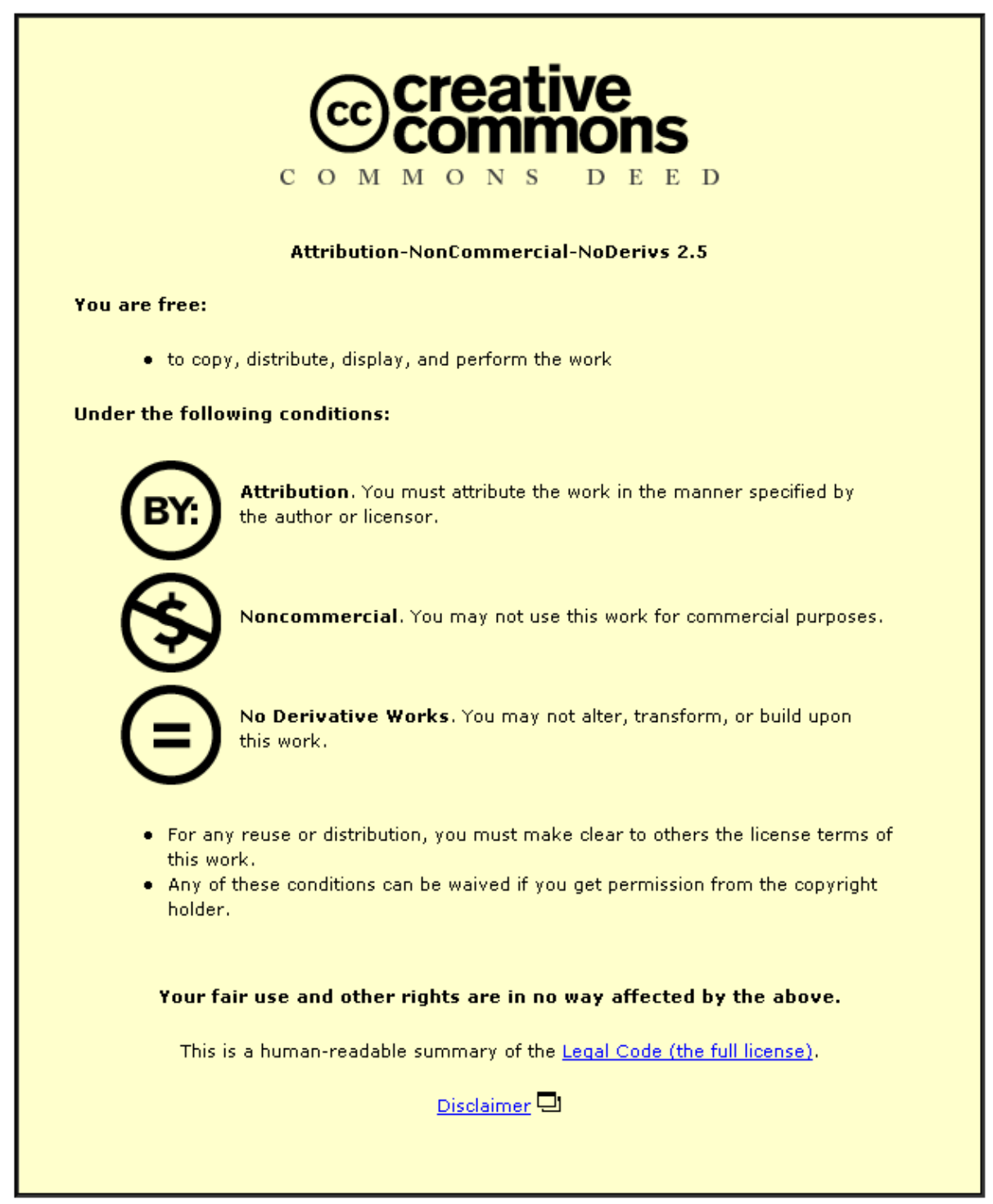

For the full text of this licence, please go to: http://creativecommons.org/licenses/by-nc-nd/2.5/ 


\title{
A Test Method and Deterioration Model for Joints and Cracks in Concrete Slabs
}

\author{
Stuart Arnold ${ }^{\mathrm{a}}$, Paul Fleming ${ }^{\mathrm{b}}$, Simon Austin ${ }^{\mathrm{b}}$, Peter Robins ${ }^{\mathrm{b}}$ \\ a) Scott Wilson Pavement Engineering Ltd, 9/10 Faraday Building, Nottingham Science and Technology Park, \\ University Boulevard, Nottingham, NG7 2QP \\ b) Department of Civil and Building Engineering, Loughborough University, Loughborough, Leicestershire, LE11 3TU
}

Keywords: (C) Cycles, (C) Degradation, (C) Durability, (C) Fatigue, (E) Concrete

\begin{abstract}
This paper reports on the development of a laboratory test method to assess the deterioration of concrete cracks and joints under low intensity, high cycle loading, typical of that found in industrial flooring, external hardstandings and rigid pavements. The half-scale prism specimen enables the impact of crack geometry, reinforcement and load magnitude to be assessed in relation to load transfer deterioration, without the need for full scale testing. Each element of the testing procedure has been developed to represent site conditions in respect to crack development, loading and support. A selection of the test results are presented which indicate that joint/crack deterioration consists of four distinct phases, each controlled by a different mechanism of material degradation. This information can be used to enhance understanding of joint/crack behaviour and their failure mechanisms, hence improving design and maintenance procedures.
\end{abstract}

\section{Introduction}

The load transfer mechanisms across any crack or joint in an internal or external hardstanding is essential to the structural capacity of the slab. If this deteriorates for any reason then there is a much greater risk of failure or serviceability problems, such as faulting (change in level across the crack), excessive deformation or further cracking. The behaviour assessment and correct simulation of each joint type with respect to load magnitude, crack orientation and long-term fatigue is therefore essential to enable designers to accurately predict slab response.

Many of the previous test methods examining small-scale monotonic or cyclic joint/crack load transfer have employed a singularly cracked specimen. Valle and Buyukozturk [1], Millard and Johnson [2] and 
others, have used a rectangular section with a shear plane induced through the centre. This arrangement is only of use for single or low numbers of repetition of load due to the method of horizontal restraint. Measurements taken during this testing showed signs of crack widening caused by stress development as aggregate particles were forced over each other. This method of normal restraint also creates rotation due to the eccentric loading, a difficult phenomenon to prevent in a singularly cracked specimen.

Similar to the work of Thompson [3], this testing utilised a double cracked shear specimen (Figure 1). The method requires a controlled crack to be induced either side of the load application position. The central section is then fixed to a loading ram with the end segments rigidly clamped against a stable surface. This caused a load differential between each side of the crack creating a double shear stress, and a reduced risk of rotation.

The research presented here describes the development of a laboratory testing facility used to examine the degradation of aggregate interlock load transfer caused by repeated load. It describes the test method in detail and indicates how each of the test parameters was altered to provide a simulation of the actions and deterioration models typical of a concrete joint or crack in a hardstanding. It also shows a typical output for a four phase failed specimen, along with a comparison of reinforcement types and quantities.

\section{Rig Development}

\subsection{Laboratory Testing}

As stated in Section 1, the laboratory testing undertaken in this research utilised a double cracked shear specimen. Although this type of crack spacing is not typical of that found within a concrete slab configuration, symmetrical degradation across both cracks produces an equivalent behaviour to a singularly cracked specimen.

To ensure representative crack behaviour was produced, it was important that the symmetrical deterioration behaviour of the two cracks was confirmed. LVDT's were placed across both crack faces with any variation in differential displacement indicating uneven crack performance. In all cases 
specimens exhibiting differentials across the crack greater than $0.2 \mathrm{~mm}$ where eliminated from any further analysis, preventing dominant crack behaviour affecting the results.

Loading of the specimen was provided by a (Dartec) cyclic loading test machine, which could apply the required load magnitude and cycle rate. A depth of $100 \mathrm{~mm}$ was used for the prism, as this was a lower bound for a $150 \mathrm{~mm}$ slab with $1 / 3$ saw cut. The width had to represent a typical section of the slab incorporating a sufficient blend of concrete constituent materials (most importantly coarse aggregate and steel fibre). As the aggregate used was below 20mm, with a maximum fibre length of $60 \mathrm{~mm}$, a value of $100 \mathrm{~mm}$ was chosen as being fully representative and having limited scale effects. A 400mm prism length enabled the central $100 \mathrm{~mm}$ section to be fixed to the load applicator, whilst providing sufficient end strapping to the reaction frame.

To simulate the type of loading found, and the degradation mechanisms within, a crack or joint in a concrete slab on grade, load was applied in both a positive (downward) and negative (upward) direction. Figure 2 demonstrates how each laboratory simulation position related to that occurring within a typical site. Position 1 is an unloaded case whereby there is no movement. When the central block is moved in a positive direction (position 2), the left hand side of the specimen represents a slab load on the leave side, whereas the specimen right hand side represents a slab load on the approach side. As the central load moves in a negative direction (position 3) the left hand side of the specimen represents a load on the approach side, with the right hand side representing a load on the leave side. This approach ensured that both the left and right hand sides of the specimen simulated a wheel load crossing the joint in either direction, and was therefore fully characteristic of the contact stresses acting across a typical in-service joint.

Within an in-service situation, loading at the end of a slab will cause bending, resulting in a gradual decrease in crack width as load is applied. Crack width is a significant factor in the degree of load transfer and differential displacement occurring within the crack; however, the point of rotation will be sufficiently far back from the crack edge (in excess of $1 \mathrm{~m}$ ) so that any horizontal movement caused by slab bending will be insignificant in comparison to the original crack width set. The aforementioned method of slab loading was therefore acceptable for simulating in-situ crack behaviour. 


\section{$2.2 \quad$ Crack Geometry}

Much of the literature available, and measurements taken from the field (detailed in Arnold [4]), suggests that the majority of joints or cracks are of a ' $\mathrm{V}$ ' shape geometry, caused by differential shrinkage and curling commonly found in concrete slabs on grade (Figure 3). The majority of the previous tests carried out on shear transfer across joints $[5,6]$ assumed a parallel width over depth and are therefore inconsistent with in-service slab conditions. White and Holley [7] examined a small number of ' $\mathrm{V}$ ' shaped cracks and compared the results to those of parallel cracking. They found that the average width of the ' $\mathrm{V}$ ' shaped crack had a greater load transfer capacity than that of a similar sized parallel crack as the aggregate contact between narrower faces dominates behaviour.

To ensure that the testing procedure and specimen preparation used in this research provided good representation of site condition, the majority of specimens were pre-cracked and set-up to obtain ' $\mathrm{V}$ ' shaped geometries. The size of the surface widths was selected from the data collected during site examination and was typically in the range of $0.5 \mathrm{~mm}$ to $6 \mathrm{~mm}$ [4]. A selection of parallel cracks was also tested to determine the effect of the crack angle, and identify any variations in behaviour.

\section{$2.3 \quad$ Subgrade Support}

Support from the underlying subbase/subgrade material partially controls the amount of vertical displacement that takes place at the slab edge when imposed by load and thereby dictates the rate of deterioration of the crack face. To simulate this, many of the tests undertaken by previous authors [8, 9], have incorporated supported slab edges, utilising either a foundation made from soil compacted in a test box, or 'elastic' materials such as neoprene pads. However, predictions of field performance become inaccurate if the processes used when testing in the laboratory are significantly different. Much of the literature $[10,11]$ and the data obtained from site testing [4] shows that in most situations the slab edges will have curled to some degree, thereby leaving the slab unsupported, with the load transfer system alone contributing to joint efficiency up to a certain load limit. This creates higher contact stress on the crack faces resulting in an increased risk of deterioration. In the test method developed here, foundation or support materials were excluded to provide the most realistic simulation of edge conditions on site. 


\section{$2.4 \quad$ Load Magnitude}

The magnitude of loading has been shown to have a major influence on the rate of concrete crack degradation [8]. A suitable value was therefore essential to represent that occurring within the field. The majority of previous tests on full-scale slabs have used a 40 to $50 \mathrm{kN}$ load over a cross sectional area of around $0.2 \mathrm{~m}^{2}$, generating a contact stress in the region of 200 to $250 \mathrm{kPa}$ [8]. The loading found on internal floor slabs varies greatly, but example values given in the literature vary between 42 and $60 \mathrm{kN}$ [12]. On external slabs this can regularly exceed $100 \mathrm{kN}$ depending on the type of vehicle used, with road pavements designed for an $80 \mathrm{kN}$ standard axle (40kN per wheel), although the actual loads can often be much higher. A reasonable value for a normalised wheel load is therefore $50 \mathrm{kN}$, with $25 \mathrm{kN}$ and $75 \mathrm{kN}$ representing low and high conditions.

To determine the equivalent load for a laboratory-scale prism it is necessary to consider load transfer. Yoder [13] and Friberg [14] proposed that for dowel bar calculations, only a distance 1.8 times the radius of relative stiffness ' $l$ ' (Equation 1) from the load source has any influence on transferring load, the effect reducing linearly with distance. The Concrete Society [12] concluded that full load transfer could be assumed at a distance $0.9 l$ either side of the load. Calculating ' $l$ ' using typical values (Youngs modulus of concrete $\left(E_{c}\right)=30 \mathrm{GPa}$, slab depth minus saw-cut $(h)=150 / 300 \mathrm{~mm}$, Poissons ratio $(v)=$ 0.15 and modulus of subgrade reaction $(k)$ varying between 0.07 and $0.01 \mathrm{~N} / \mathrm{mm}^{3}$, produces results in the range of 0.6 to $1.5 \mathrm{~m}$, which when doubled incorporating the effect either side of the load, along the slab edge gives full load transfer lengths between 1.2 and $3 \mathrm{~m}$. If the average of these values is used to simulate a typical situation (i.e. $2 \mathrm{~m}$ ), with an effective slab depth (minus saw-cut) equal to $0.1 \mathrm{~m}$, and a load $(P)$ of $50 \mathrm{kN}$, Equation 2 generates a contact stress $(\tau)$ of $250 \mathrm{kPa}$.

To produce a similar $250 \mathrm{kPa}$ contact stress in the laboratory-scale specimens, where beam width $(x)$ and depth $(d)$ are equal to $0.09 \mathrm{~m}$ (doubled as there are two crack faces), an applied load $(P)$ of $+/-4 \mathrm{kN}$ was required (Equation 3). When smaller and larger loads with equivalent full-scale magnitudes of 25 and $75 \mathrm{kN}$ were considered, an applied force of $+/-2 \mathrm{kN}$ and $+/-6 \mathrm{kN}$ was required.

$$
\begin{array}{ll}
l=\left[E_{c m} h^{3} / 12\left(1-v^{2}\right) k\right]^{0.25} & \text { Equation 1 } \\
\tau=P /(2 l \cdot d) & \text { Equation 2 }
\end{array}
$$




$$
P=2 \tau(x \cdot d)
$$

Equation 3

\section{$2.5 \quad$ Loading repetition}

The crack or joint of a slab may be subjected to hundreds of load repetitions every day, resulting in many millions of cycles throughout its expected lifespan. Given the research period and typical timespans available for testing, it was impractical for loading to continue for a full life cycle and therefore a representative value had to be adopted. Colley and Humphrey [8] tested large-scale slabs for up to one million cycles and concluded that $90 \%$ of the degradation will have occurred within the first 500,000 cycles. Abdel-Maksoud [15] conducted similar tests on smaller samples at cycle numbers up to 300,000 cycles, at which point the increase in degradation appeared to have ceased. Thompson [3] examined cement bound materials and stopped testing after 10,000 cycles as the gradient of shear slip displacement had reduced dramatically.

Due to the range of load cycles used in the tests reviewed, 15 trial tests were conducted with the proposed test method to ascertain the most appropriate number for this research. A minimum of 250,000 cycles was chosen initially, with a further 250,000 applied on 5 specimens to examine longerterm deterioration. At least $75 \%$ of the 500,000 cycles differential displacement occurred within the first 250,000 cycles, with 8 specimens failing completely. This level of repetition was therefore selected as an appropriate representation of final degradation.

In the majority of experiments the displacement/cycle gradient was found to reduce to negligible values towards the end of the test. However, in a few samples appreciable levels of deterioration were still visible as indicated by the steady increase in gradient. In these circumstances the test was continued until a horizontal gradient was found (normally shortly after), although the 250,000 cycle data was still used for comparison during analysis.

\section{$2.6 \quad$ Load rate}

Colley and Humphrey [8] measured the loading pattern of a joint as a vehicle travels over at approximately 50kph. This required the approach slab to be loaded from zero to maximum in 0.25 seconds, and then instantaneously removed. On completion the leave slab was immediately loaded and 
gradually reduced to zero in 0.25 seconds, resulting in a total cycle length of 0.5 seconds. Due to the nature of the small-scale tests, and the limitations of the Dartec testing machine, it was not possible to fully replicate the approach used by Colley and Humphrey [8]; however, a sinusoidal curve that completes a full cycle in 0.5 seconds was employed (Figure 4). Abdel-Maksoud [15] concluded from his work on cyclic loading that the load rate has very little impact on degradation results unless weak aggregate is used, and therefore this approach to loading was considered to be acceptable.

\section{Test Specimen Preparation}

\subsection{Specimen Production}

The specimens were constructed using the concrete mix specified in Table 1 . This was similar to that identified in several steel fibre reinforced internal floor slabs constructed within the past 5 years. Three hook end steel fibre types with aspect ratios of 48, 67 and 80 , and a tensile strength of $1000 \mathrm{~N} / \mathrm{mm}^{2}$, were incorporated into the mix where required, with a single bar of A142 steel fabric or $7 \mathrm{~mm}$ reinforcement bar also used for the relevant tests. Each specimen was stripped after 24 hours and water cured at $20^{\circ} \mathrm{C}$ for a minimum of 28 days. The specimens were then tested as soon as possible after this 28 day curing period, with a maximum limit until the first test of 42 days. Specimens within the same batch were tested consecutively, limiting the variation in age to 12 days.

\subsection{Crack Timing}

The test prisms needed to be pre-cracked prior to testing in the cyclic loading rig. Work carried out by Abdel-Maksoud [15] concluded that the formation of a crack is highly dependent upon the time at which it is instigated. When formed early in the life of the concrete i.e. within 48 hours, it is the bond between aggregate and cement paste which breaks down. After this period the bond has had time to strengthen and an increased percentage of cracking will occur through the aggregate. This change in crack type causes large variation in the roughness of the face and therefore affects aggregate interlock [15]. The Concrete Society [12] has determined that cracking in concrete floor joints generally occurs in the first 24 to 48 hours of slab life when the concrete has limited strength but is subjected to tensile stress. This leads to matrix cracking producing the more roughened surface described above. The test prisms were therefore also pre-cracked at this early time period. As the crack width required for each 
test would not be known at such an early stage, each beam was initially cracked to the smallest $0.7 \mathrm{~mm}$ surface width and then enlarged once the required test width required was known. This enabled the final measurement to be determined later on in the testing schedule, but ensured the profile would reflect that of an early-age crack.

\subsection{Crack Technique}

The method of crack formation has been found to influence the roughness of the crack face [15]. Abdel-Maksoud [15] criticised the techniques used by other researchers for not providing suitable simulation to that found on in-service slabs. He suggested that a three point bending technique would produce a much smoother face compared to a true tensile crack, caused by crack formation through the aggregate rather than around it and resulting in a decrease in shear transfer available through interlock. The assumption is that crack development in slabs on grade is instigated from a true tensile stress caused by shrinkage. Walker and Holland [11] have stated that cracking is often created by curling of the concrete slab rather than direct shrinkage, resulting in a mixture of both tension and flexural forces.

From the monitoring of cracks in-situ by Arnold [4] and the literature reviewed [10, 16], it has been shown that the geometry of a crack or joint in concrete slabs is generally ' $\mathrm{V}$ ' shaped due to differential shrinkage. A method was therefore required to enable this crack geometry to be re-produced in smallscale prisms. Thompson [3] developed a simple three-point bending crack induction method proven to produce a vertical crack continuous across the specimen. This involved incremental loading at the crack location until the equipment control software detected a load reduction, at which point loading ceased and a crack was assumed. The beam was then rotated 180 degrees and reloaded enabling a parallel crack to develop. Examination of different methods of crack induction resulted in the method suggested by Thompson [3] being used as it could easily be adapted to produce a 'V' shaped crack through loading of one side only.

The modified technique involved sawing to a depth of approximately $5 \mathrm{~mm}$ around the circumference of the beam to enable the crack positions to be set. The beam was then placed on steel blocks and shims set $90 \mathrm{~mm}$ either side of the saw cut. A similar sized block, but with no shim, was placed directly underneath the saw cut and a round steel bar placed on top. Load was then applied at a controlled rate 
creating a flexural crack increasing in size until it hit the block underneath, at which point all load was removed. For the second saw cut position the beam was repositioned and cracked in a similar manner. The method is shown diagrammatically in Figure 5.

\subsection{Crack Width Control}

A series of trial tests was undertaken to examine the applicability and accuracy of the cracking technique. A predicted opening was calculated for several shim sizes using standard geometrical rules. Demec pips were then placed across each of the notches $(10 \mathrm{~mm}$ from the top and bottom of the specimen) and measurements taken before and after crack formation. Extrapolation of these measurements enabled top and bottom openings to be calculated (equivalent to the surface and base of a slab).

The results demonstrated that the cracking method produced consistent and reproducible results, but with smaller surface crack widths than predicted (Figure 6). The experimental results indicate that the crack width obtained is 1.73 times larger than the shim used (with a correlation coefficient of 0.92). This is significantly lower than the predicted value of 2.22 times the shim size. On inspection the crack was found to close slightly once loading ceased due to the resistance of the reinforcement. To avoid this affecting the results during the cyclic load testing, the pre-cracking width was set 1 shim $(0.66 \mathrm{~mm}$ surface crack width) smaller than required. This allowed the final crack size to be formed when clamping the beam in the cyclic load test rig, ensuring that closure and slack within the fibres or reinforcement did not influence the results.

Testing was also undertaken to confirm that the cracks created in the rig were linear (i.e. did not open up proportionally more in the top section of the prism compared to the bottom). Demec pips were placed at 10mm intervals across both sides of the two cracks and measurements taken before and after loading. An almost perfectly linear relationship was found with an $\mathrm{r}^{2}$ value of 0.92 . 


\section{Test procedure}

The test rig consisted of two steel side blocks on which the relevant shim combinations were placed, with the test prism positioned on top. All were rigidly clamped to the test frame, forcing the beam into an angled position and opening the cracks to the required size and geometry. The central section was strapped to the crosshead via a $50 \mathrm{kN}$ load cell, which was linked directly back into the Dartec test machine allowing load magnitude to be monitored and adjusted as required (Figure 7). Two linear variable differential transducers (LVDT's) were mounted vertically on the front face of the concrete specimen with one vertical and one horizontal mounted on the rear (Figure 8). This enabled vertical and horizontal displacement and rotation to be monitored throughout the test.

Data from the cyclic loading tests was recorded with a Campbell Scientific CR10X data logger and the PC208 computer software. At each 5 minute (600 cycle) interval, data was collected for 0.5 seconds, enabling one complete $2 \mathrm{~Hz}$ load cycle to be recorded. During this period fifty LVDT and load readings were taken.

The maximum and minimum displacements were then determined from each cycle, and plotted against cycle number to show the effect of crack degradation (Figure 9). The difference between each maximum and minimum value for an individual cycle was calculated and plotted against cycle number to monitor the vertical crack movement and deterioration. Plots of individual cycles were also examined where required to determine the source of the joints load resistance.

Visual examinations were made of the specimens periodically throughout each test. This involved assessing the amount, size and type of any ejected material caused by deterioration of the crack face. In fibre-reinforced specimens the behaviour and failure mode of the fibre could also be identified by examining those close to the prism surface. Once the test was complete the specimen was broken open across the crack face (if reinforcement was still holding it together) and the visual condition identified. This could include excessive face cracking, aggregate looseness or loss of reinforcement bond. 


\section{Joint Behaviour}

\subsection{Specimens Tested}

In total, 82 specimens were tested over the course of the research period. Table 2a provides the composition of each specimen mix, with Table 2b indicating the crack widths at which each specimen type was tested.

\section{$5.2 \quad$ Joint Failure}

Two key types of evidence were examined to build a picture of joint behaviour within a slab resisting cyclic loading: the magnitude of, and change in, the vertical movement (i.e. the maximum differential displacement of each face of the joint during a cycle), and the shape of the time/displacement plot (which is indicative of how load is being transferred between the two crack faces). Observing these parameters over time enabled identification of transition points between phases of behaviour and hence development of a simple model of joint deterioration.

As stated earlier, each prism was tested up to 250,000 cycles, with some specimens continued for up to 500,000 cycles to examine longer-term deterioration patterns. Sixteen specimens failed within the planned cycle limit with load transfer becoming negligible and displacements very large, limited only by the restraints of the loading apparatus. The differential displacement at which the specimens began to degrade rapidly varied from 0.6 to $1.14 \mathrm{~mm}$, with a mean of $0.85 \mathrm{~mm}$ and standard deviation of 0.28 . A lower bound of $1.6 \mathrm{~mm}$ was identified as the boundary for load transfer failure. In these situations the number of cycles to failure provided some indication of the strength and durability of the joints load transfer system.

\subsection{Phases of Deterioration}

The sixteen specimens that failed completely helped identify four distinct phases of deterioration, with the displacement differential versus cycle plots producing similar patterns of behaviour (Figure 10).

During phase I, rapid deterioration occurred resulting in a steep gradient. After approximately 10,000 cycles the joint stabilised and moved into phase II where a much lower and approximately linear 
degradation was observed. These two phases were seen in all 82 specimens tested regardless of the reinforcement type and quantity used. In the tests causing specimen failure, phase III was identifiable, whereby the differential displacement increases until reaching a magnitude of approximately $1.2 \mathrm{~mm}$. At this point the specimen enters phase IV where the displacements increase rapidly and failure is likely to occur within the next 10,000 cycles.

This four phase behaviour was similar regardless of the crack width used, fibre reinforcement quantity and load magnitude. The main difference between the specimens was the rate at which the specimens reached the different phases, with those containing reinforcement at the highest quantity, the lowest loading magnitude and smallest crack width, withstanding greater load cycles before moving into the proceeding phase. However, the magnitude of differential displacement at which the deterioration phases change varies only slightly between each phase.

\subsection{Mechanism of Load Transfer}

The shape of the differential displacement versus cycle number plot is influenced by the reinforcement type/quantity and changing aggregate interlock mechanisms as the system degrades. From this, and observations of the joints, it is possible to summarise joint and crack behaviour.

During phase I the mortar deteriorates quickly, it being a relatively weak material. Once this has transpired the increase in deflection slows due to the greater strength and bonding of the larger aggregate particles (phase II). As failure commences in phase III the aggregate begins to debond from the surrounding mortar, cracks in the matrix are initialised and the concrete face begins to degenerate. This increases the stresses on the remaining particles creating further cracking until such a point that phase IV is entered, whereby negligible load transfer is available through the aggregate interlock mechanism.

The influence of reinforcement such as steel fibres or fabric delays the onset of the proceeding phase. The mortar deterioration still occurs as shown by the steep gradient in phase I; however, the reinforcement transfers some of the load and lowers the contact stress in the crack face. This reduces the rate of deterioration and delays the onset of phase III. 
In specimens where the differential displacement was low, very little material spalled from the crack; however, on completion of the test a small layer of dust could be seen. On those where movement was higher ( $0.2 \mathrm{~mm}$ or above) the amount of dust generated was much greater, but all of the larger $10-20 \mathrm{~mm}$ aggregate appeared to be intact. In specimens that were close to failure, sections of concrete up to $20 \mathrm{~mm}$ in size spalled from the base of the prism on either side of the crack, along with large amounts of cement dust. Loose large aggregate particles of $10-20 \mathrm{~mm}$ diameter, which had become detached from the surrounding matrix, could also be seen on the sides and top of the prism, and were only prevented from ejection by the support of the surrounding material. Upon failure the entire surface of the crack began to break away, resulting in a large amounts of spalled material.

\subsection{Influence of Specimen Parameters}

The full suite of experimental results are too comprehensive to be included here; however, Figure 12 provides an overview of the results obtained from the testing and presents a summary of material behaviour and resistance to deterioration.

The incorporation of steel fibre reinforcement increased the number of cycles that could be withstood before phase III crack deterioration began to take place. Increasing the quantity of steel fibres from 20 to $40 \mathrm{~kg} / \mathrm{m}^{3}$ also reduced the rate of deterioration and lowered the magnitude of differential displacement taking place. The introduction of steel fabric or traditional reinforcement reduced the differential displacement still further and ensured failure did not occur in those specimens tested.

As expected, surface crack width was a key factor in the controlling joint deterioration, with the smaller widths (typically $0.9 \mathrm{~mm}$ ) showing significantly better resistance to degradation than surface cracks of $4.2 \mathrm{~mm}$ or larger.

Full information on the results for each of the material parameters can be found in Arnold [4] and Austin et al [17]. 


\section{Conclusions}

A small-scale laboratory test rig has been developed to investigate the cyclic load transfer of sawn joints and cracks in concrete ground-bearing slabs. It avoids expensive and time consuming large-scale testing, and facilitates the examination of failure modes and the controlled variation of key joint and reinforcement parameters in a relatively straightforward manner. Unlike most other tests it can simulate crack geometries, support and loading typical of real joints and cracks in ground-bearing slabs, with cracks formed in a ' $\mathrm{V}$ ' formation as in a curled area (hence little ground support) with wheel loading that reverses the shear action during each cycle.

The results obtained from the test procedure provide a valuable insight into joint and crack degradation. A simple model of joint behaviour under cyclic loading is proposed, comprising four main phases. An increase in differential displacement over 250,000 loading cycles was obtained for a variety of concrete and reinforcement specifications. A rapid increase in displacement over the first few thousand cycles of around $0.3 \mathrm{~mm}$ was found, caused by degradation of the fine aggregate. After this there was a period of slow change whereby larger aggregate particles began to bear upon one another. In those specimens where failure transpired a third section of rapidly increasing differential displacement occurred. Here, the aggregate cracked and debonded from the remainder of the concrete, creating higher stresses across the crack face and therefore quicker degradation. A differential of around 1.6mm was found to coincide with rapid deterioration to failure with no significant load transfer.

Information obtained from the testing will inform clients, operators and designers of the deterioration process of cracks and joints in concrete slabs on grade. Their long-term serviceability can be assessed and the worst-case scenarios designed for, to help ensure that deflections under load do not become excessive, thereby damaging materials handling equipment and slowing down operational procedures. The intervention of remedial works can be reduced and also, where necessary, lower the time and cost impacts on the business operations.

\section{7. $\quad$ References}

[1] M. Valle, O. Buyukozturk, Behaviour of Fiber Reinforced High Strength Concrete under Direct Shear, ACI Materials Journal, 90 (2) 1993 122-133. 
[2] S.G. Millard, R.P. Johnson, Shear Transfer Across Cracks in Reinforced Concrete due to Aggregate Interlock and Dowel Action, Magazine of Concrete Research 36 (126) 1984 9-21.

[3] I. Thompson, Use of Steel Fibres to Reinforce Cement Bound Roadbase, PhD Thesis, The University of Nottingham, Nottingham, England, 2001.

[4] S.J. Arnold, Load Transfer across Cracks/Joints in Concrete Slabs on Grade, PhD Thesis, Loughborough University, Loughborough, England, UK, 2004.

[5] N. Buch, M.A. Frabizzio, J.E. Hillier, Impact of Coarse Aggregates on Transverse Crack Performance in Jointed Concrete Pavements, ACI Materials Journal 97 (3) 2000 325-331.

[6] Z.I. Raja, M.B. Snyder, Factors Affecting Deterioration of Transverse Cracks in Jointed Reinforced Concrete Pavements, Transportation Research Record 1307, Transportation Research Board, 1991 162-168.

[7] R.N. White, M.J. Holley, Experimental Studies of Membrane Shear Transfer, Journal of the Structural Division, American Society of Civil Engineers 98(ST8) 1972 1835-1853.

[8] B.E. Colley, H.A. Humphrey, Aggregate Interlock at Joints in Concrete Pavements, Development Department Bulletin D124, Portland Cement Association, Illinois, 1967.

[9] W.J. Nowlen, Influence of Aggregate Particles on Effectiveness of Interlock Joints in Concrete Pavements, Journal of the PCA Research and Development Laboratories, Report D139 10 (2) 1968.

[10] M. Poblete, R. Valenzuela, Load Transfer in Undoweled Transverse Joints of PCC Pavements, Transportation Research record 1207, Transportation Research Board 1988 39-49.

[11] W.W. Walker, J.A. Holland, Plate Dowels for Slabs on Ground - Dowels for the 21st Century, Draft Copy, Loughborough University, 2001.

[12] Concrete Society, Concrete Industrial Ground Floors - A Guide to design and Construction, Technical Report No.34, 3rd ed. Crowthorne, UK, 2003.

[13] E.J. Yoder, Principles of Pavement Design, John Wiley \& Sons Inc, Chichester, England, 1959 435-452.

[14] B.F. Friberg, Design of Dowels in Transverse Joints of Concrete Pavement, Proceedings of the American Society of Civil Engineers 64 (9) 1938 1809-1828.

[15] M.G. Abdel-Maksoud, Behaviour of Concrete Joints Under Cyclic Shear, PhD Thesis, University of Illinois, USA, 2000.

[16] J. Bishop, The Early Age Behaviour of Concrete Industrial Ground Floor Slabs, PhD Thesis, Loughborough, England, 2001.

[17] S.A. Austin, S.J. Arnold, P.R. Fleming, P.J. Robins, The Influence of Steel Reinforcement in Reducing the Deterioration of Concrete Cracks and Joints under Low-intensity, High Cycle Loading, Draft Paper, Loughborough University, Loughborough, England, UK, 2004. 
Table 1 - Specimen Concrete Mix

\begin{tabular}{|c|c|}
\hline Material & Quantity \\
\hline Cement & $370 \mathrm{~kg} / \mathrm{m}^{3}$ \\
\hline Coarse Aggregate $(5-10 \mathrm{~mm})$ & $355 \mathrm{~kg} / \mathrm{m}^{3}$ \\
\hline Coarse Aggregate $(10-20 \mathrm{~mm})$ & $711 \mathrm{~kg} / \mathrm{m}^{3}$ \\
\hline Fine Aggregate & $783 \mathrm{~kg} / \mathrm{m}^{3}$ \\
\hline Free water & $185 \mathrm{~kg} / \mathrm{m}^{3}$ \\
\hline
\end{tabular}

Table 2a-Specimen Composition

\begin{tabular}{|c|c|c|c|c|c|}
\hline $\begin{array}{l}\text { Specimen } \\
\text { Code }\end{array}$ & $\begin{array}{c}\text { Concrete } \\
\text { Mix }\end{array}$ & $\begin{array}{c}\text { Reinforcement } \\
\text { Type }\end{array}$ & $\begin{array}{c}\text { Reinforcement } \\
\text { Quantity }\end{array}$ & $\begin{array}{l}\text { Applied } \\
\text { Load }\end{array}$ & $\begin{array}{c}\text { Crack } \\
\text { Geometry }\end{array}$ \\
\hline $\mathbf{A}$ & Standard & None & - & $4 \mathrm{kN}$ & 'V' \\
\hline B & Mortar & Fibre (67) & $30 \mathrm{~kg} / \mathrm{m}^{3}$ & $4 \mathrm{kN}$ & 'V' \\
\hline $\mathbf{C}$ & Standard & Fibre (67) & $20 \mathrm{~kg} / \mathrm{m}^{3}$ & $4 \mathrm{kN}$ & 'V' \\
\hline D & Standard & Fibre (67) & $30 \mathrm{~kg} / \mathrm{m}^{3}$ & $4 \mathrm{kN}$ & 'V' \\
\hline $\mathbf{E}$ & Standard & Fibre (67) & $40 \mathrm{~kg} / \mathrm{m}^{3}$ & $4 \mathrm{kN}$ & 'V' \\
\hline $\mathbf{F}$ & Standard & Fibre (80) & $30 \mathrm{~kg} / \mathrm{m}^{3}$ & $4 \mathrm{kN}$ & 'V' \\
\hline $\mathbf{G}$ & Standard & Fibre (48) & $30 \mathrm{~kg} / \mathrm{m}^{3}$ & $4 \mathrm{kN}$ & 'V' \\
\hline $\mathbf{H}$ & Standard & Reinforcing Bar & $1 \times 7 \mathrm{~mm} \phi \mathrm{Bar}$ & $4 \mathrm{kN}$ & 'V' \\
\hline $\mathbf{I}$ & Standard & Steel Fabric & $1 \times 6 \mathrm{~mm} \phi$ Bar & $4 \mathrm{kN}$ & 'V' \\
\hline $\mathbf{J}$ & Standard & Fibre (67) & $30 \mathrm{~kg} / \mathrm{m}^{3}$ & $2 \mathrm{kN}$ & 'V' \\
\hline $\mathbf{K}$ & Standard & Fibre (67) & $30 \mathrm{~kg} / \mathrm{m}^{3}$ & $6 \mathrm{kN}$ & 'V' \\
\hline $\mathbf{L}$ & Standard & Fibre (67) & $20 \mathrm{~kg} / \mathrm{m}^{3}$ & $4 \mathrm{kN}$ & Parallel \\
\hline $\mathbf{M}$ & Standard & Fibre (67) & $30 \mathrm{~kg} / \mathrm{m}^{3}$ & $4 \mathrm{kN}$ & Parallel \\
\hline $\mathbf{N}$ & Standard & Fibre (67) & $40 \mathrm{~kg} / \mathrm{m}^{3}$ & $4 \mathrm{kN}$ & Parallel \\
\hline
\end{tabular}

Notes:- Standard concrete mix details are as detailed in Table 1.

Fibre Types are differentiated using aspect ratio.

Table 2b - Specimens Tested

\begin{tabular}{|c|c|c|c|c|c|}
\hline \multirow{2}{*}{$\begin{array}{c}\text { Specimen } \\
\text { Code }\end{array}$} & \multicolumn{5}{|c|}{ Surface Crack Width } \\
\cline { 2 - 6 } & $\mathbf{0 . 7} \mathbf{m m}$ & $\mathbf{2 . 0 m m}$ & $\mathbf{3 . 3 m m}$ & $\mathbf{4 . 6 m m}$ & Other \\
\hline $\mathbf{A}$ & 2 & 2 & - & - & - \\
\hline $\mathbf{B}$ & 2 & - & - & - & - \\
\hline $\mathbf{D}$ & 2 & 2 & 2 & 2 & $1 \times 4.0 \mathrm{~mm}$ \\
\hline $\mathbf{E}$ & - & 2 & 3 & 2 & $2 \times 5.9 \mathrm{~mm}$ \\
\hline $\mathbf{F}$ & - & 2 & 2 & 2 & $2 \times 5.9 \mathrm{~mm}$ \\
\hline $\mathbf{G}$ & - & 2 & 2 & 3 & - \\
\hline $\mathbf{H}$ & - & 2 & 3 & 3 & - \\
\hline $\mathbf{I}$ & - & 2 & 1 & 2 & - \\
\hline $\mathbf{J}$ & - & 2 & 2 & 2 & - \\
\hline $\mathbf{K}$ & - & 2 & 2 & 3 & - \\
\hline $\mathbf{L}$ & 2 & 3 & - & - & - \\
\hline $\mathbf{M}$ & 2 & 2 & - & - & - \\
\hline $\mathbf{N}$ & 2 & 2 & - & - & - \\
\hline
\end{tabular}




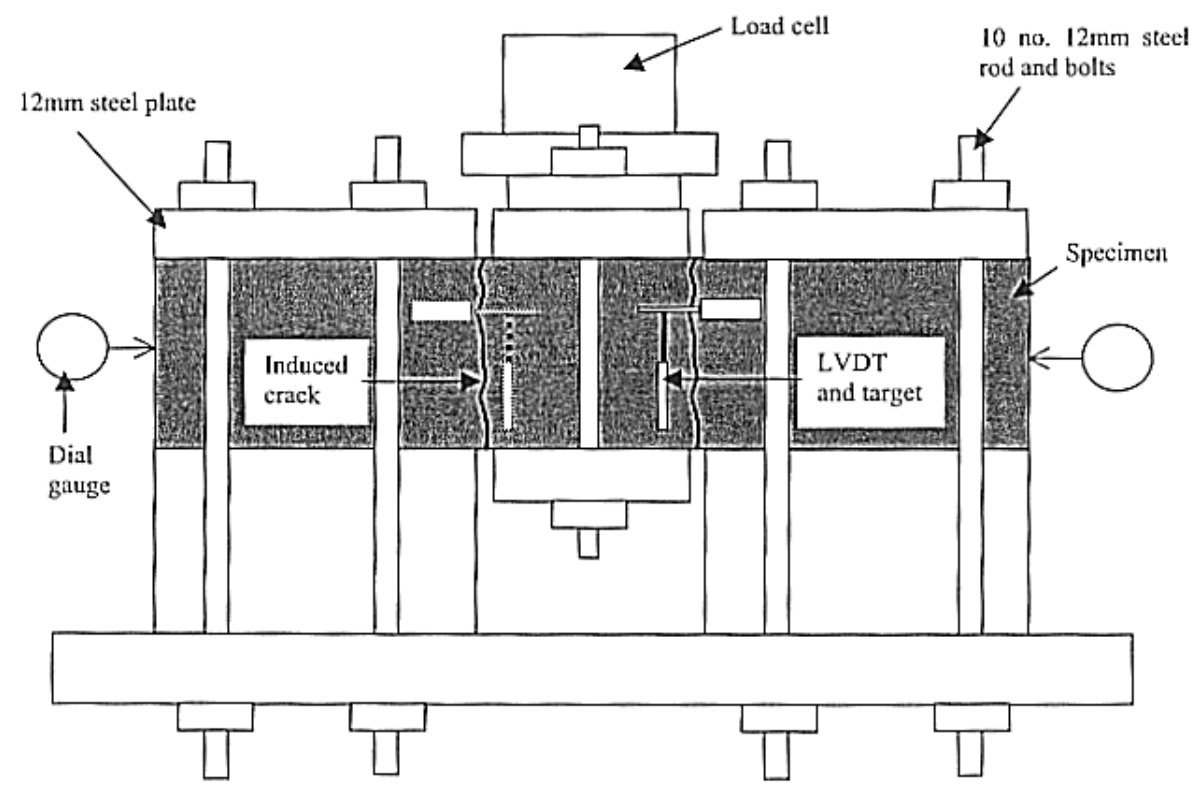

Figure 1 - Double Crack Test Set-up for Cyclic Loading [7] 


\section{Position 1 - Neutral}
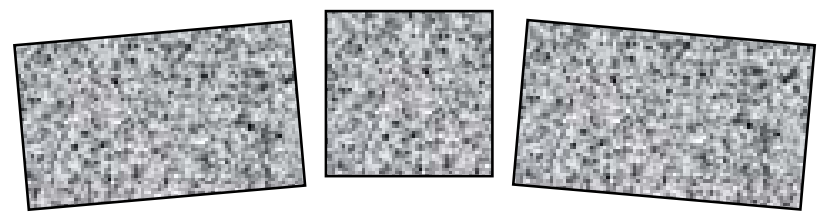

Position 2 - Positive Load

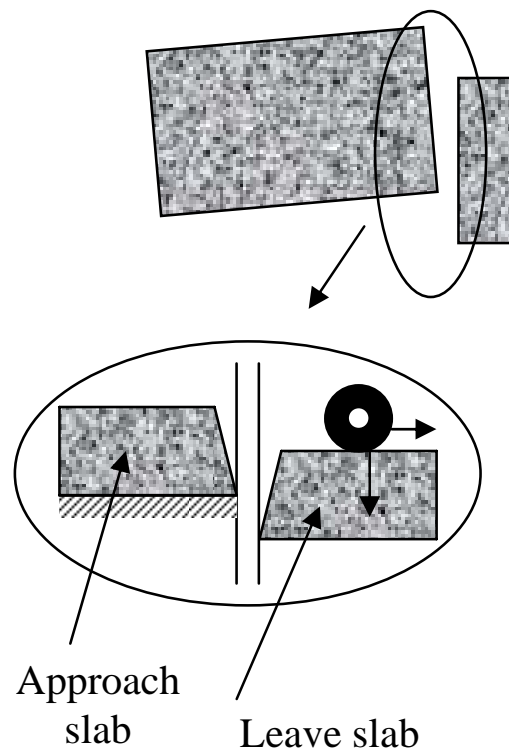

Position 3 - Negative Load

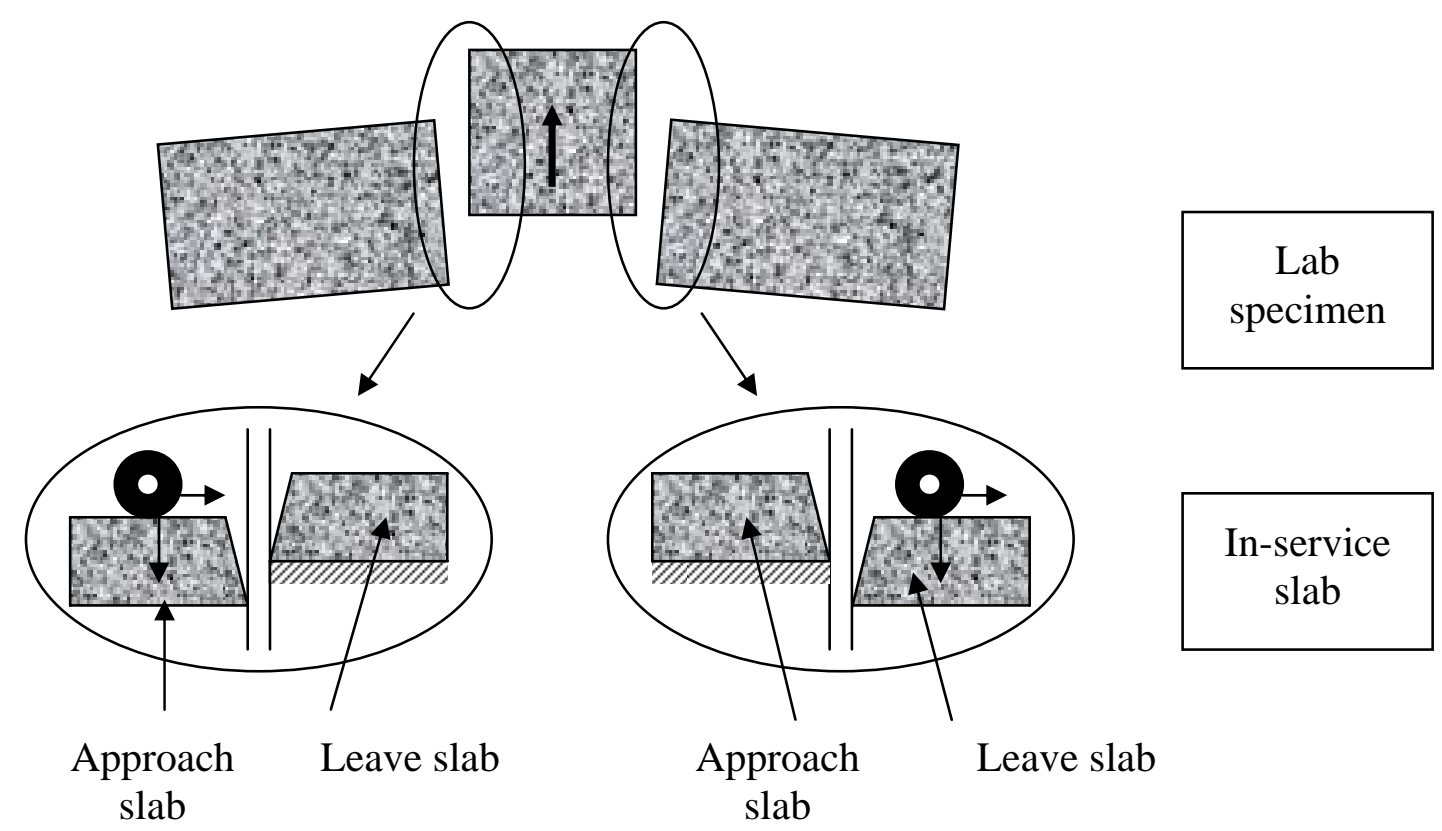

Figure 2 - Representation of In-service Slab Loading using Positive and Negative Laboratory Loading 


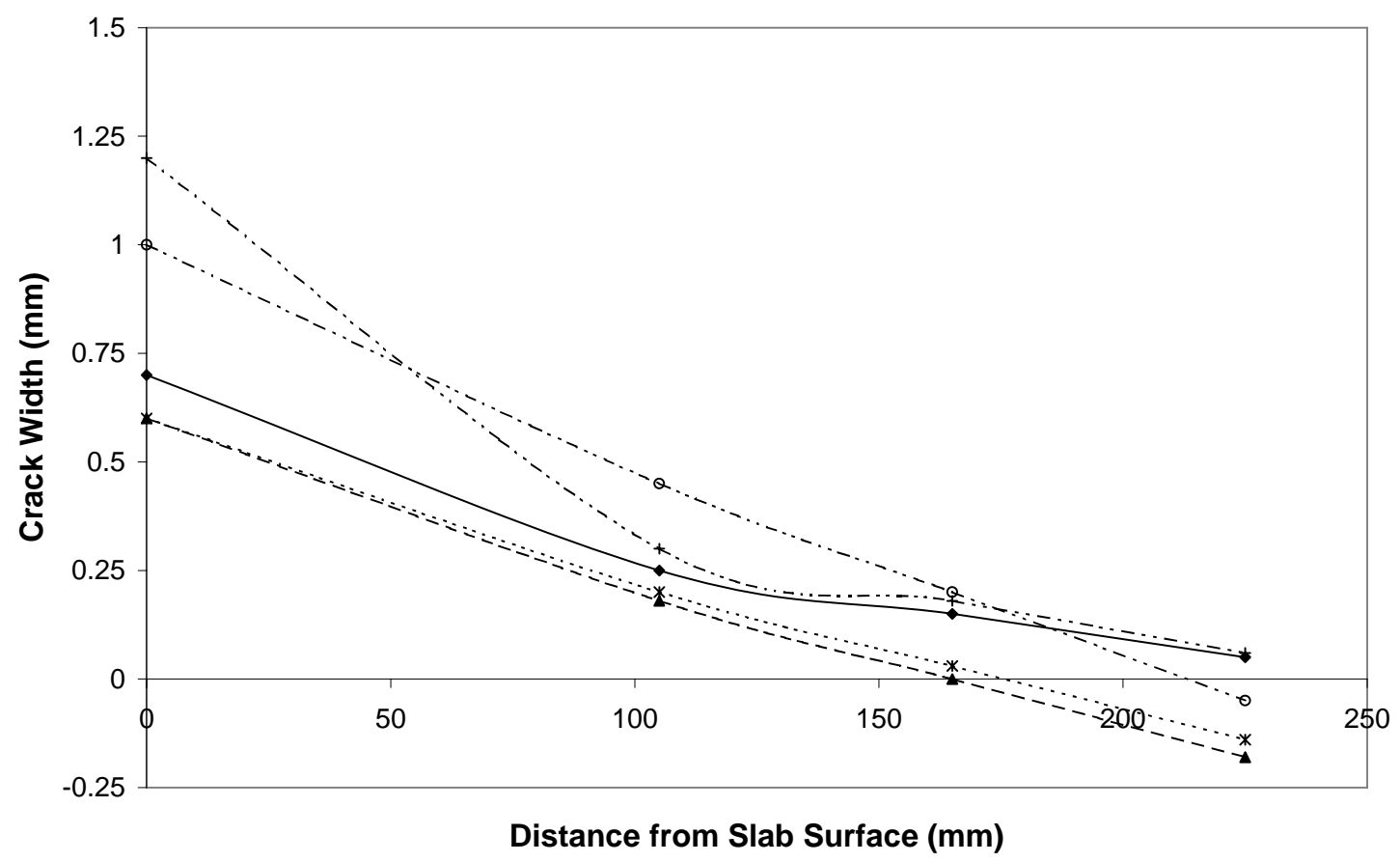

Figure 3 - Geometry of In-service Slab Joints 


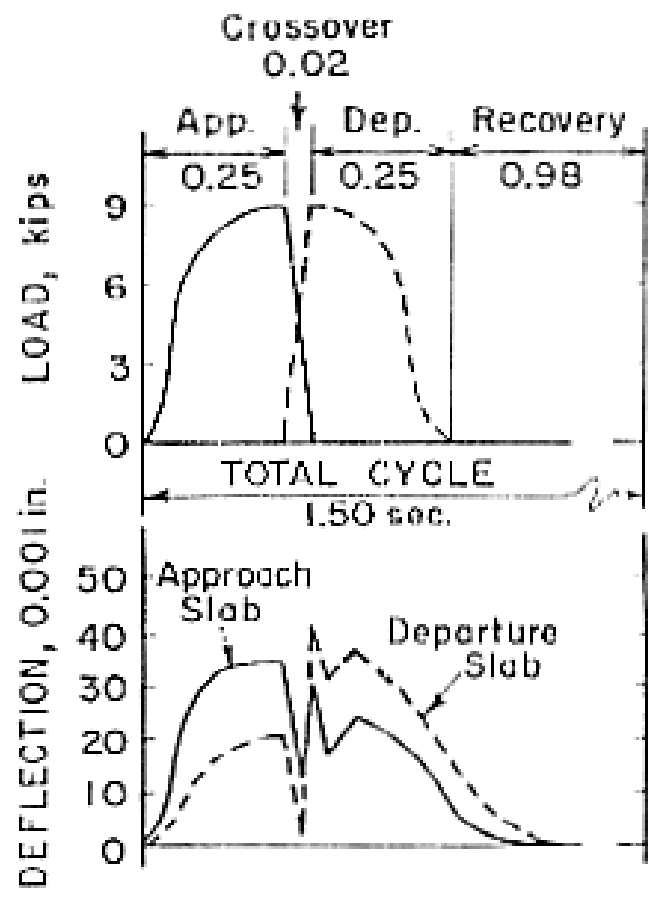

Figure 4(a) -Colley and Humphrey Measured Deflection Cycle [11]

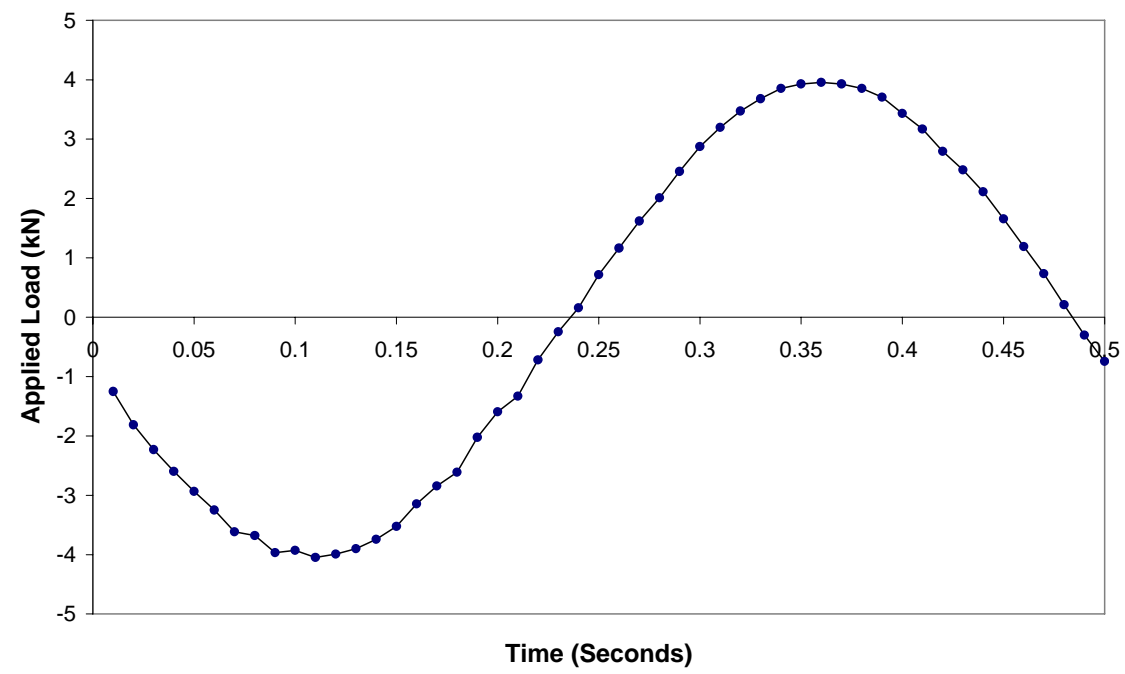

Figure 4(b) -Laboratory Testing Deflection Cycle [4] 
Saw-cut of $6 \mathrm{~mm}$ depth placed circumfrentially

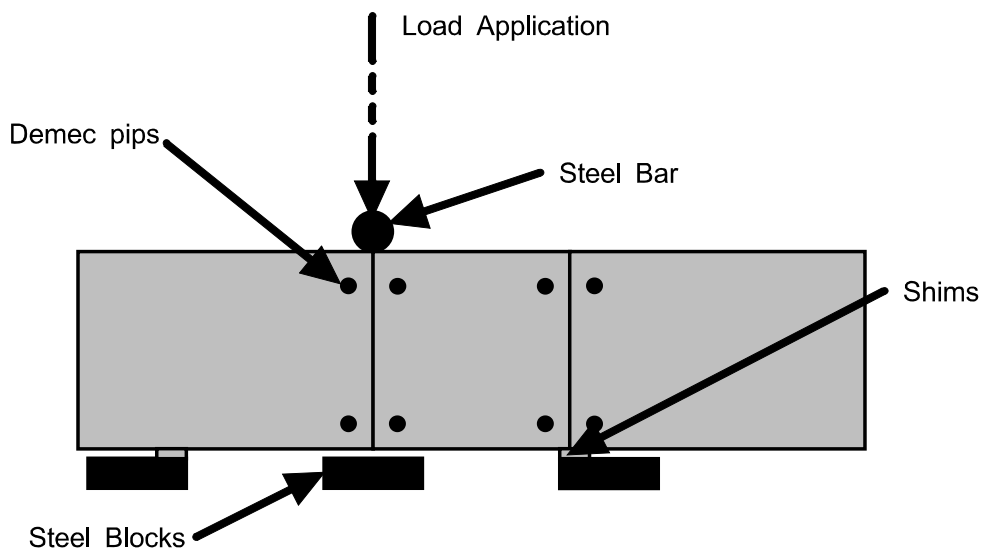

3 Point Bending to Form First Crack, Shim Size Controls Dimensions

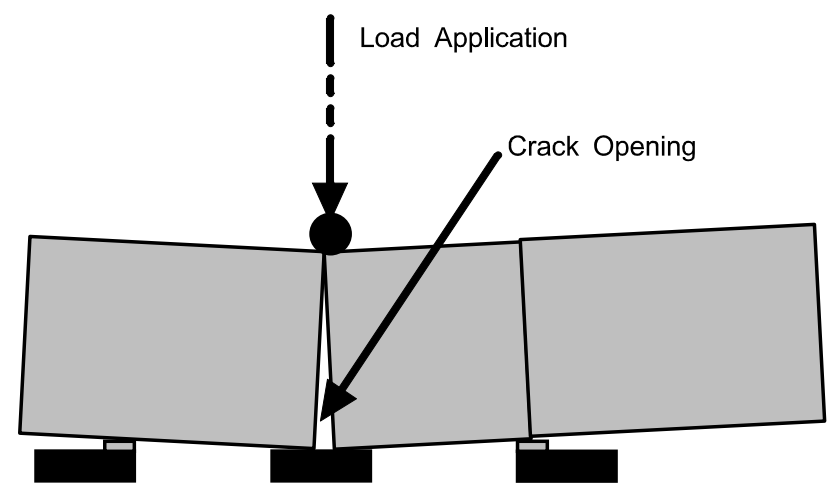

Second Crack Formed, Beam may be Inverted to Produce Parallel Geometry

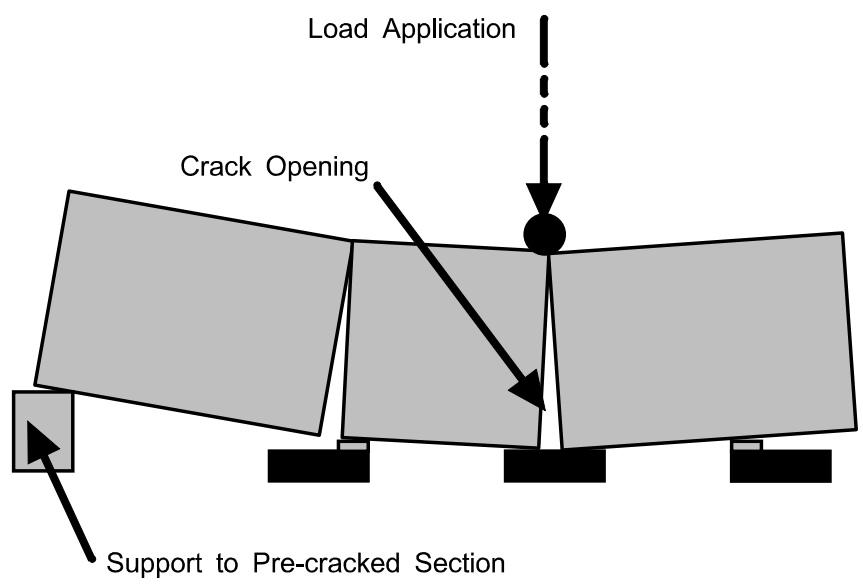

Figure 5 - Laboratory Specimen Crack Development Methodology 


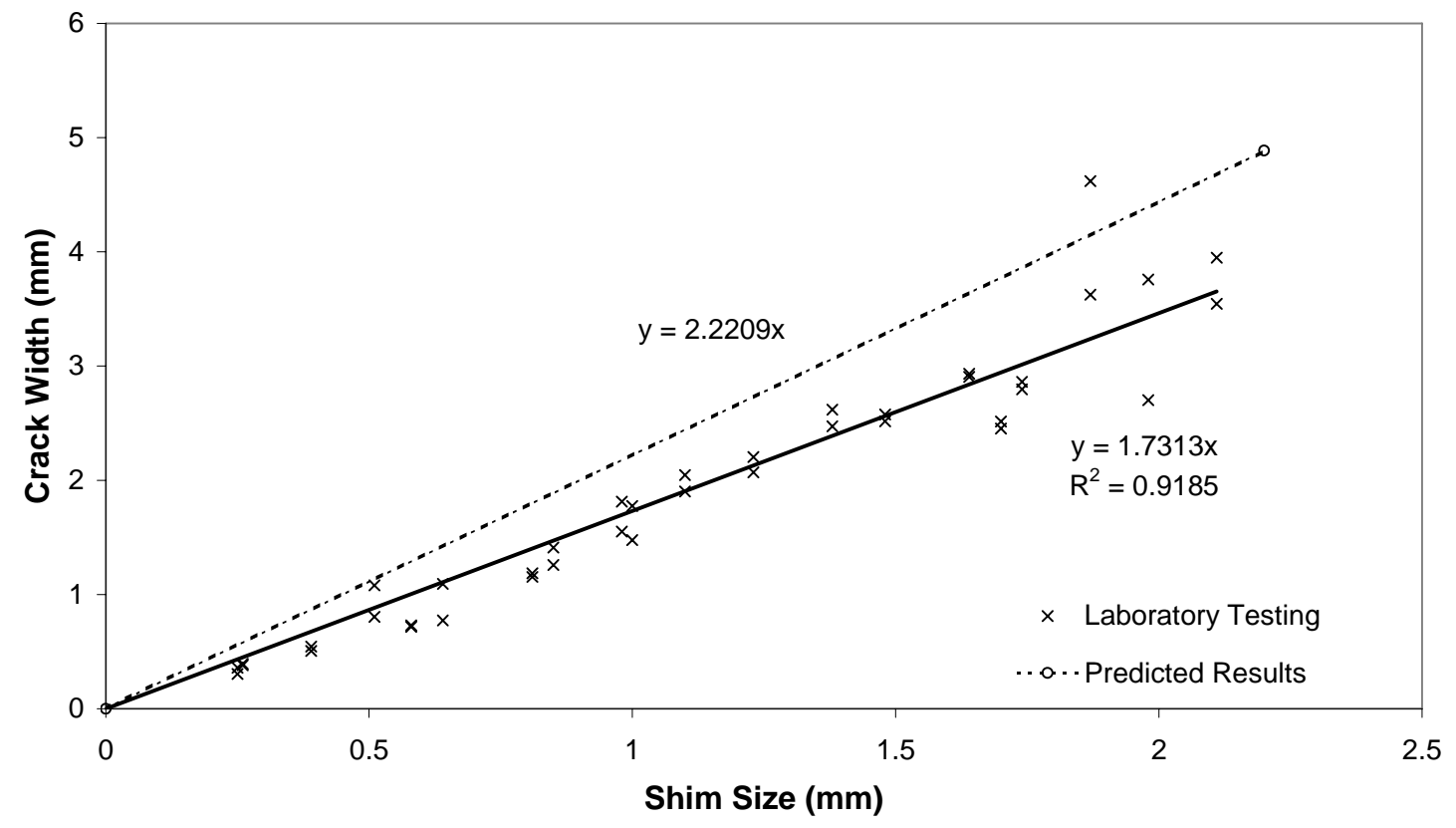

Figure 6 - Comparison of Predicted and Actual Surface Crack Measurements 


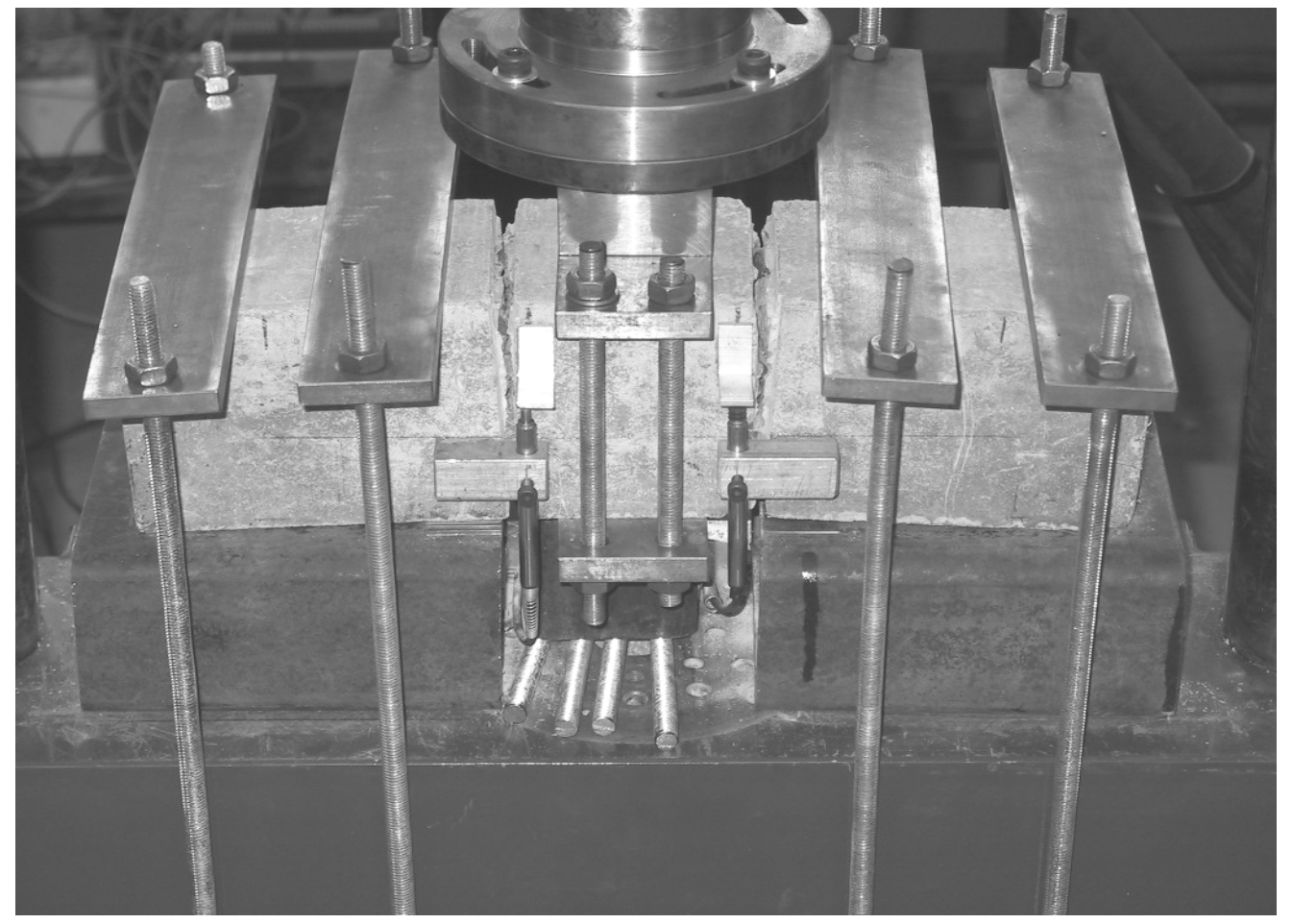

+/- Load Cycle (2Hz)

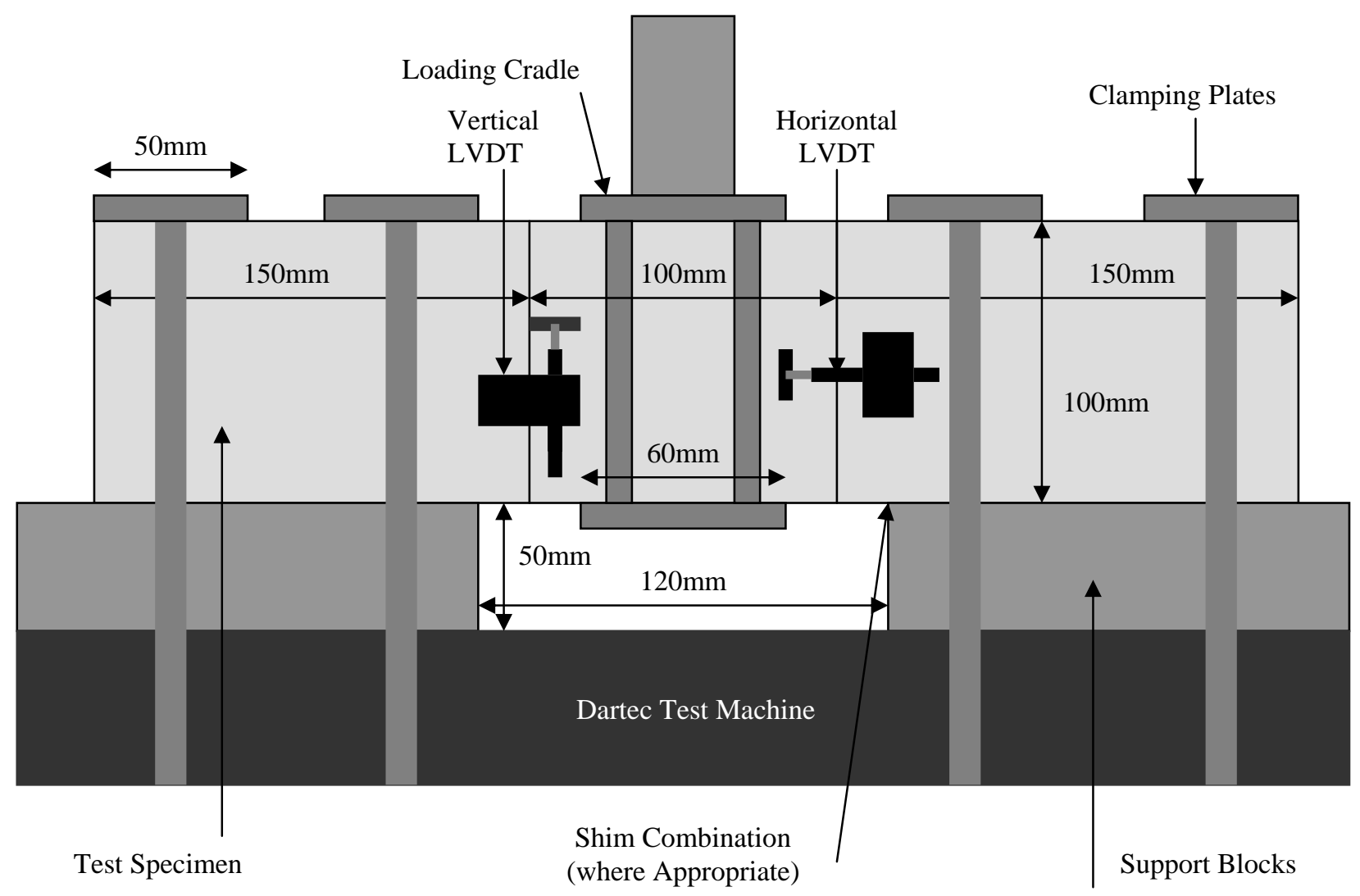

Figure 7 - Arrangement of Test Rig 

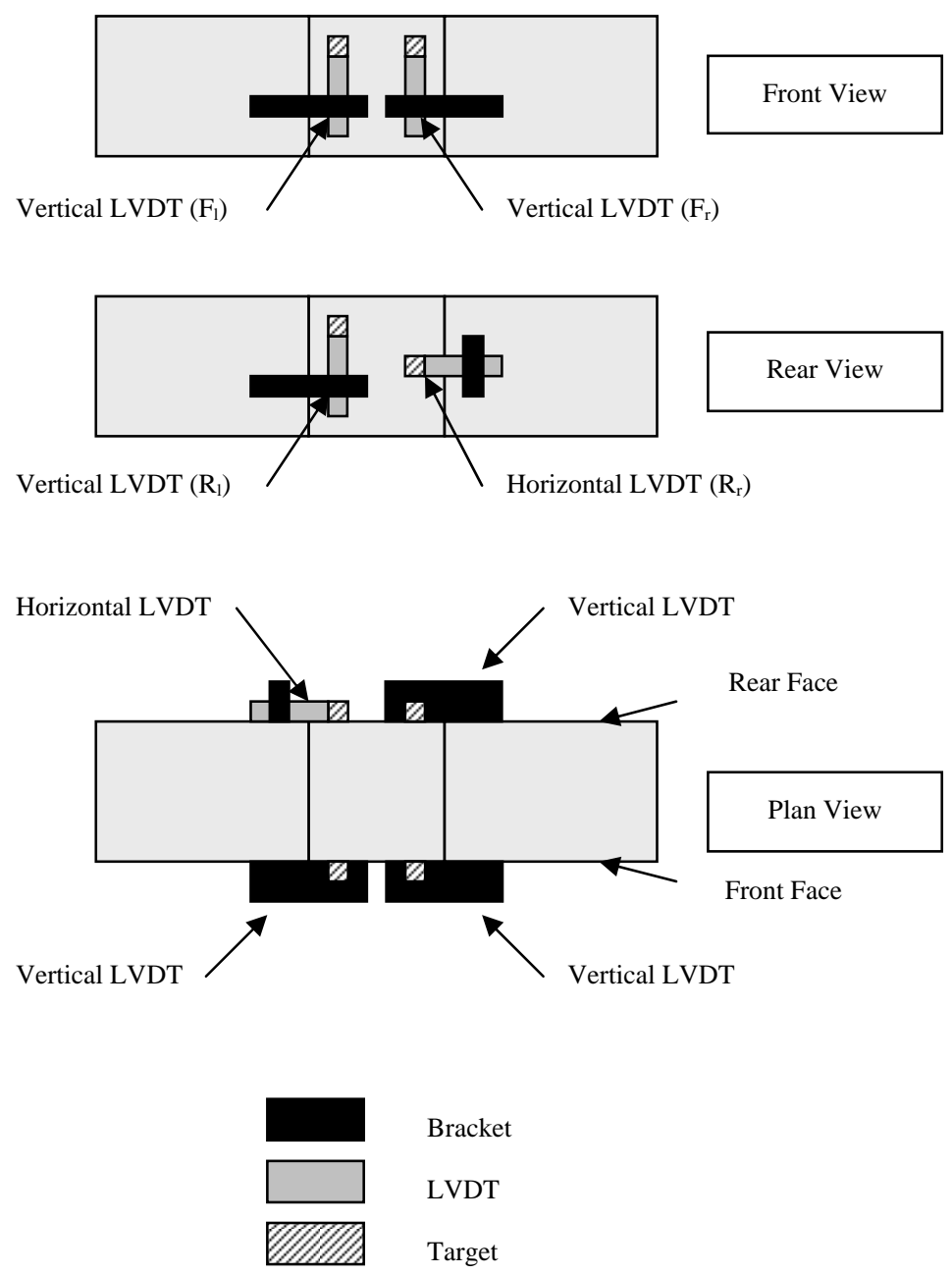

Figure 8 - LVDT Positioning 


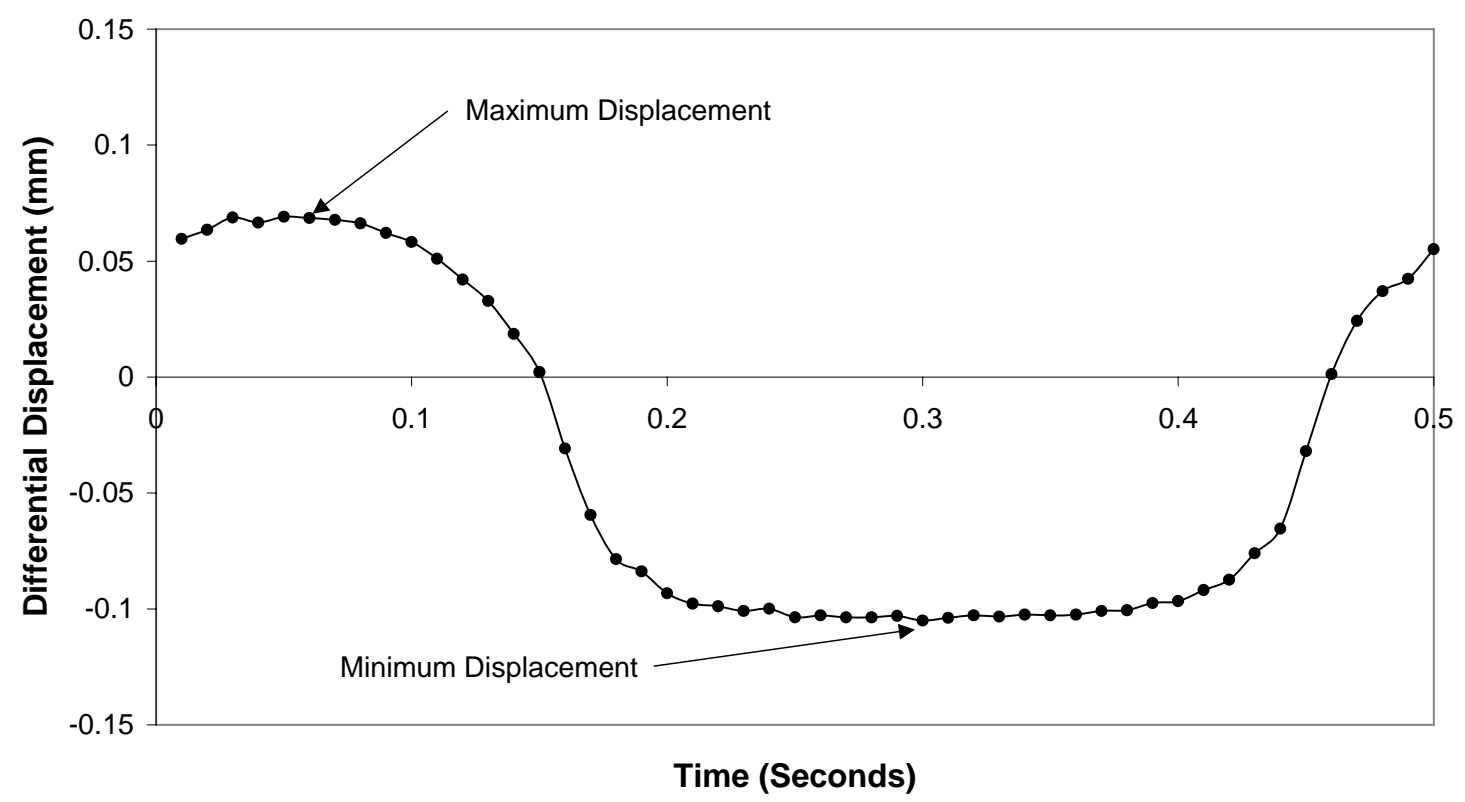

Figure 9 - Typical Time/Displacement Plot for an Individual Load Cycle 


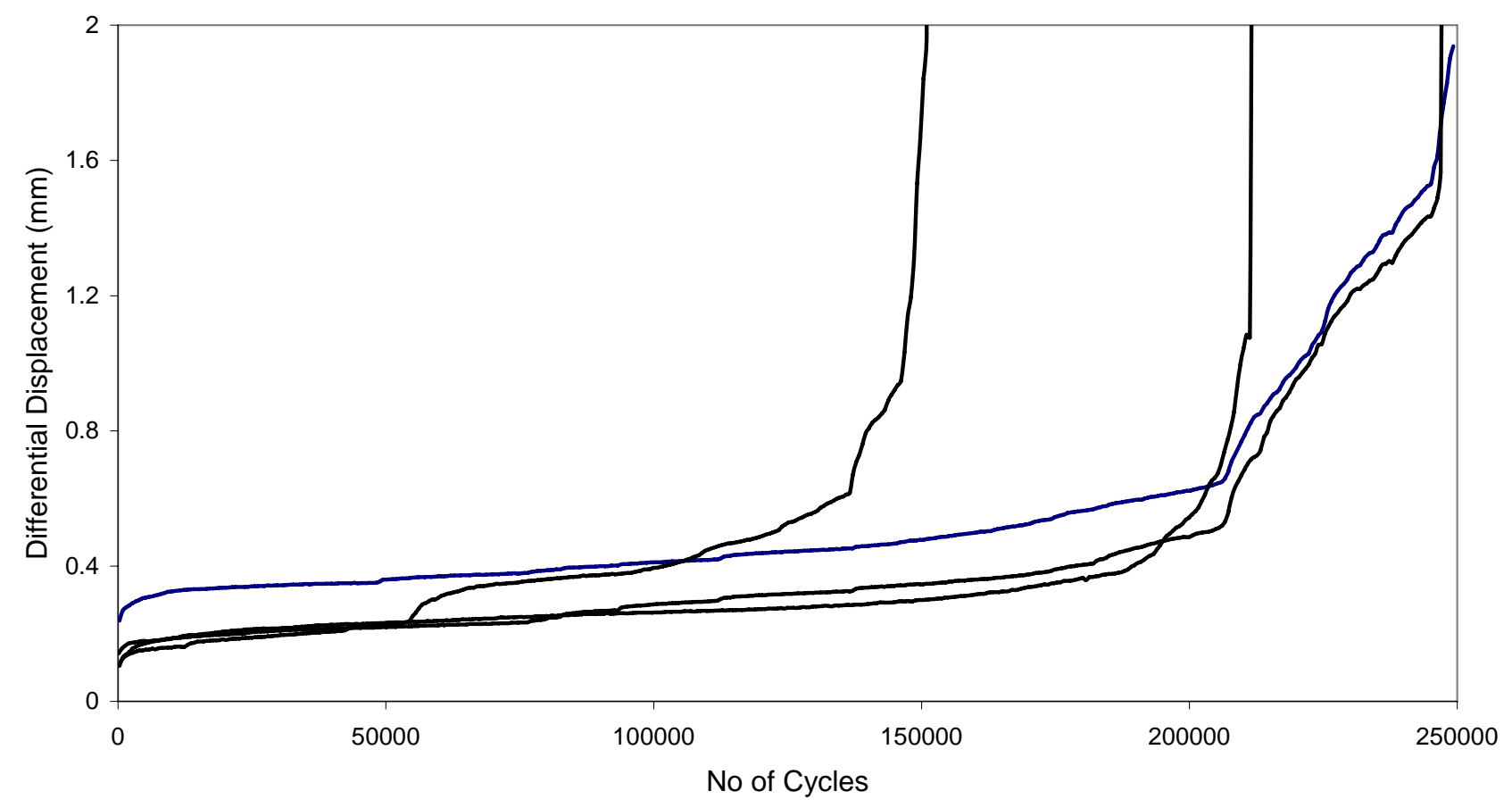

Figure 10 -Deterioration to Failure of Test Specimens 


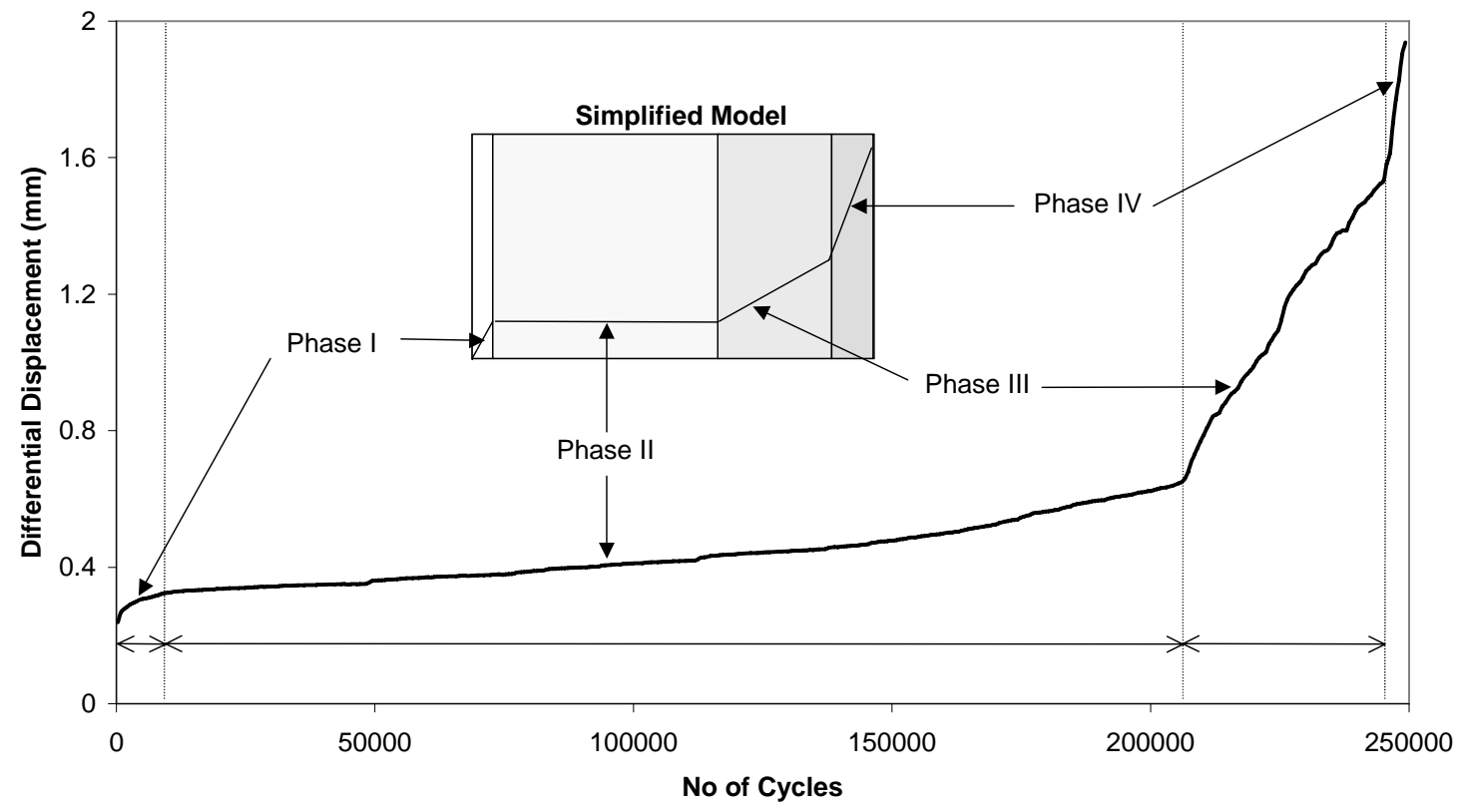

Figure 11 - Deterioration Phases of a Concrete Crack 


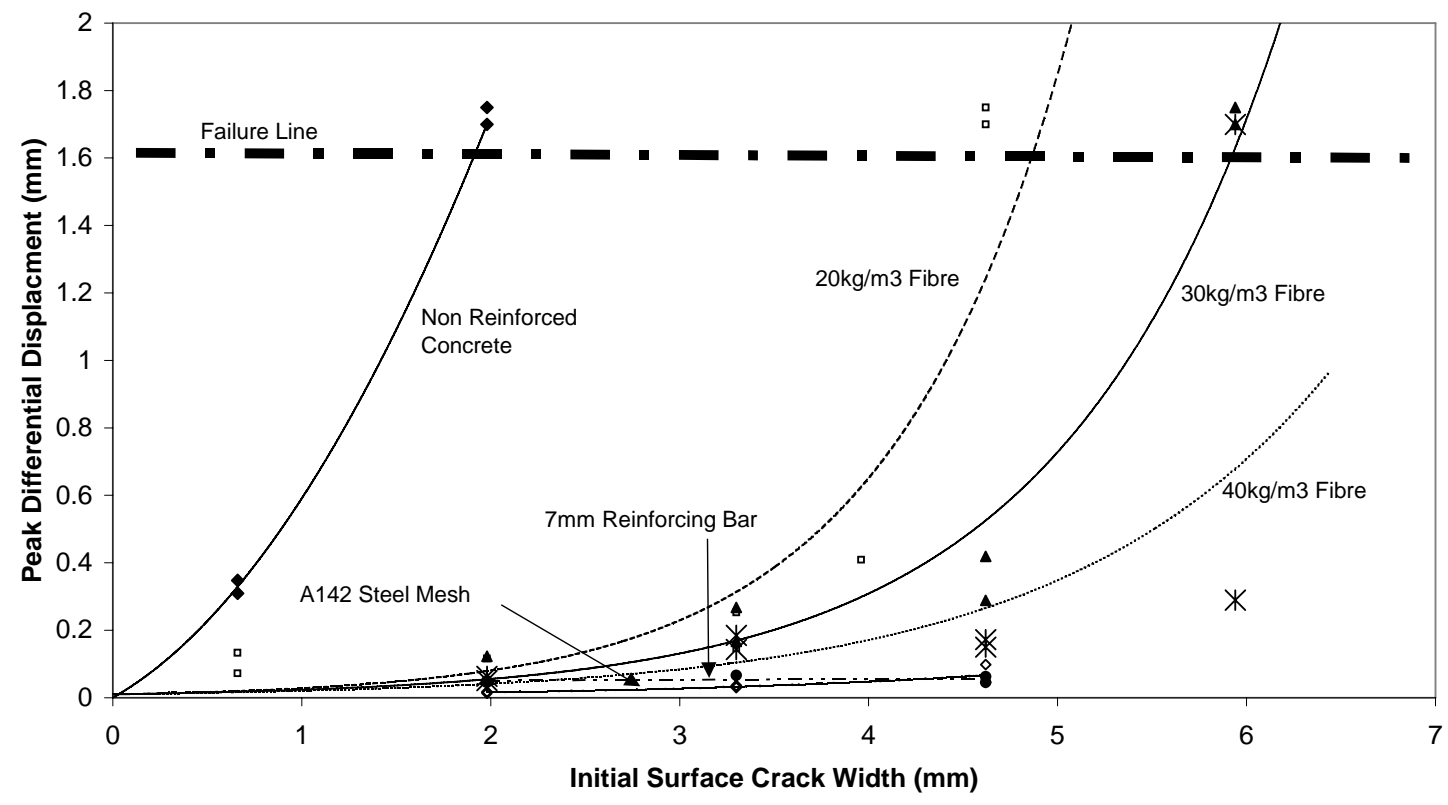

Figure 12 - Effect of Reinforcement Type and Quantity on Differential Displacement 